\title{
QUANTIFIED TREE RISK ASSESSMENT USED IN THE MANAGEMENT OF AMENITY TREES
}

\author{
By Michael J. Ellison
}

\begin{abstract}
A system of tree risk assessment is proposed that expands concepts developed by others and enables a probability of significant harm to be applied to tree failure risk. By evaluating the components of a tree failure hazard and assigning to them estimates of probability, the proposed system enables the skilled tree inspector to calculate the product of those probabilities to produce a numerical estimate of risk. The use of quantification in the assessment of tree hazards enables property owners and managers to operate, as far as is reasonably practicable, to a predetermined limit of reasonable or acceptable risk.

Key Words. Risk assessment; tree hazards; safety; target; quantified risk; amenity; saproxylic habitat.
\end{abstract}

Tree managers work in a climate of increasing environmental awareness, in which trees are greatly valued and yet potentially hazardous. There is, therefore, a need to reconcile different management objectives, especially on sites where old and perhaps structurally unstable trees are present. As trees age, they increasingly develop features that might compromise their mechanical integrity while providing increasingly diverse wildlife habitats and visual interest. These features include cavities and decaying wood, which together with other niches in the tree, provide habitats for many rare plants and saproxylic (deadwood) animals and fungi (Kirby and Drake 1993). In Britain, a large proportion of such trees occur in rural areas, but there are also many on the streets of towns and in gardens, churchyards, and city parks.

If old trees and their younger successors are to be managed responsibly with regard both to safety and their value, methods must be developed for the reliable assessment of hazards and valuable features alike. As far as hazards are concerned, the need is to be able to quantify them and any associated risk so that the risk can be kept within acceptable or reasonable limits without implementation of disproportionate risk control measures.

This paper introduces quantified tree risk assessment, which is an expansion of concepts proposed by Paine (1971), Helliwell (1990, 1991), and Matheny and Clark (1994). Quantified tree risk assessment provides a framework for the assessment of the three components of tree failure risk-target value, probability of failure, and impact potential. By first assessing the value or use of targets upon which trees might fail, tree owners and site managers can establish whether and at what degree of rigor tree inspections are required. By assessing the probabilities of the three components and calculating their product, it is possible for the skilled tree assessor to quantify the risk of significant harm from tree failure in a way that enables owners and managers to balance safety with tree values.

\section{DEFINITION OF TERMS Hazard}

"A hazard is the disposition of a thing, a condition, or a situation to produce injury" (Health and Safety Executive 1995). A tree failure hazard is present when a tree has potential to cause harm to people or property.

\section{Probability}

Statistical probability is a measure of the likelihood of some event happening. There are rules of addition and multiplication in probability theory. In tree failure risk assessment, the probability that the three components will combine in a common outcome is the product of their independent probabilities.

\section{Risk}

Risk is the probability of something adverse happening. "Quantified risk assessment is a risk assessment which incorporates numerical estimates... There are many forms of risk and therefore of risk assessment. The underlying concept is that of seeking to identify in some quantitative or at least comparative way the connection between some hazardous agency, and actual exposure to harm" (Health and Safety Executive 1995).

\section{Acceptable Risk}

We are constantly exposed to and accept or reject risks of varying degrees. For example, if we desire the convenience of electric lighting, we must accept that, having implemented control measures such as insulation and periodic inspection, there is a low risk of electrocution; this is an everyday risk taken and accepted by millions of people.

When evaluating tree failure hazards, two types of risk must be considered. We must consider the person upon whom a risk is imposed, as with the neighbor of a tree 
owner, and the person who accepts some degree of risk in return for a benefit, such as a tree owner or visitor to a woodland or forest.

Having considered The British Medical Association Guide's Living with Risk (Henderson 1987) and with particular reference to the conclusion "few people would commit their own resources to reduce an annual risk of death that was already as low as 1/10,000," Helliwell (1990) suggests that 1/10,000 might be a suitable figure to start with as the limit of acceptable risk. Furthermore, "for members of the public who have a risk imposed on them 'in the wider interest,' HSE [Health and Safety Executive] would set this limit at 1/10,000 per annum" (Health and Safety Executive 1996). In the management of trees, a property owner or manager might adopt the 1/10,000 limit of acceptable risk or choose to operate to a higher or lower level.

\section{Cost and Benefit}

Trees confer many benefits, being essential to our well being and generally enhancing our built and natural environments. Removal of all tree hazards would lead to certain impoverishment in the quality of human life. Therefore, it is necessary to maintain a balance between the benefits of risk reduction and the costs of that risk reduction, not only financially but also in terms of lost amenity and other tree-related benefits.

\section{Value of Statistical Life}

Value of statistical life is a term used in risk assessment to express the monetary value of an individual life. In the United Kingdom, this value is currently in the region of $£ 750,000$ to $£ 1,000,000$ (US $\$ 1,387,500$ to US $\$ 1,850,600$ ) (Health and Safety Executive 1995) and is proposed here to correlate the value of damage to property with the value of human life.

\section{HAZARD ASSESSMENT}

For a tree failure hazard to exist, two criteria must be fulfilled. There must be potential for failure of the tree and potential for injury or damage to result. The issue that the tree manager must address is the likelihood, or risk, of a combination of factors resulting in harm, and the likely severity of harm.

Most tree defects can be identified and assessed by the skilled inspector, but there is no evaluation methodology currently in general use that enables the inspector to quantify risk in a way that the risks associated with the retention of trees can be compared with a broadly acceptable level of risk.

A landowner or manager with responsibility for a diverse tree population, on a site comprising locations as disparate as a boundary with a busy highway, a children's play area, and a remote woodland walk, must rely on the subjective judgment of the tree inspector, employed at any point in time, when formulating management strategies and allocating budgets. Such subjectivity could result in the implementation of remedial work, perceived by the current tree inspector to be necessary for the abatement of a hazard and possibly resulting in unnecessary cost and degradation of both the amenity and conservation value of a site, without having first established the risk of significant harm arising from the hazard.

Probably the most significant recent development in the field of tree hazard evaluation is the methodology proposed by Matheny and Clark (1994). Designed primarily to assist the evaluation of tree failure hazards in urban areas, the system is relatively easy to apply and enables tree inspectors and managers to prioritize remedial action in a structured manner. The guide proposes a system of rating tree failure hazards by assessing and applying a numerical value of 1 to 4 to each of the three components that contribute to a tree failure hazard: (1) failure potential, (2) size of the tree part that could fail, and (3) target rating. The sum of the three equally weighted scores is termed the "hazard rating." A hazard rating of 12 represents the most severe hazard. The system enables the broad prioritization of tree failure hazards but does not quantify the associated risks.

\section{THE PROPOSED SYSTEM}

Quantified tree risk assessment is not a wholesale departure from current practice, but it quantifies risk within a structured framework and utilizes, but renames, the three components of the tree hazard proposed by Matheny and Clark (1994): (1) probability of failure, (2) impact potential, and (3) target value. The system enables quantification of the independent probabilities of the three components, enabling their product (risk of harm) to be compared with a generally accepted level of risk. The quantified tree risk assessment process might, in areas of very high access, involve the detailed inspection and assessment of every tree, or might, in low-access areas, require only a general overview of trees and targets. To simplify the assessment process, probabilities are presented in ranges in Tables 3, 5 , and 6 (e.g., $1 / 1$ to $1 / 19$ and $1 / 20$ to $1 / 100$ ).

A probability of death or serious injury of $1 / 10,000$ is suggested as the limit of acceptable risk to the public at large (Helliwell 1990; Health and Safety Executive 1996). Using the $1 / 10,000$ limit, all risks with a probability exceeding $1 / 10,000$ require remedial action to reduce the risk to an acceptable level, unless the risk is limited to a particular individual or group-such as a tree owner-who may choose to accept a greater or lesser risk. Additionally, the hazard could confer benefits that might be set against the risk of harm.

\section{Target Evaluation}

A target is anything of value that could be harmed in the event of tree failure. Frequent inspection of trees and assessment of associated risks may be essential in areas of high public access or where trees are within striking range of valuable or fragile structures. Conversely, in a location 
without structures and having very low public access, assessment of tree hazards may be unnecessary. The target value is the most significant and most easily quantified element of the assessment. In quantified tree risk assessment, evaluating the nature of the targets within a survey area before the assessment of trees enables the tree manager to prioritize inspections and establish whether and at what degree of rigor an inspection is required.

Often the nature of the defect is such that the probability of failure is greater during high winds, while the probability of the site being occupied during such weather conditions is considerably reduced (e.g., woodland, park, or private garden). People may venture beneath trees during high winds either in the pursuit of recreation, thus voluntarily contributing to their increased exposure to harm from tree failure, or out of necessity, such as en route from home to a workplace. Even in the latter example, weather conditions may be so extreme that the risk of harm from the failure of not only trees but the collapse of buildings and other storm-related hazards is such that to venture out at all would be foolhardy.

Helliwell (1991) proposed that the probability of a tree falling onto a road and actually hitting or being hit by a vehicle can be established by determining the ratio of the average length of time the section of road is occupied by vehicles to the total length of time in a day, and calculating the probability of a vehicle being in, or within the stopping distance of, the target area. Such a methodology is em- ployed here to assess the probability of target sites being occupied by vehicles or pedestrians.

The proposed system considers three types of target. Tables 1 and 2 illustrate the calculation of vehicle and pedestrian frequencies. Vehicle and pedestrian targets and the repair value of damage to structures are combined in Table 3.

\section{Vehicles}

The occupation of vehicular targets (Table 1 ) is evaluated using 1996 vehicle frequency statistics for standard road classifications (Transport Statistics Great Britain 1997).

Large trees standing adjacent to most classes of road have potential to impact vehicles traveling in both directions on a road. Motorways (U.S. equivalent: freeways and interstate highways) are an exception; trees in Great Britain do not have the potential to fall across all lanes of a motorway. Vehicle numbers for motorways are therefore halved (Table 1) because only half of the road is being considered as the target. In the case of vehicles, probability of impact may relate either to the tree part striking the vehicle or to the vehicle striking the fallen tree part. Both types of impact are influenced by vehicle speed. The faster a vehicle travels, the less likely it is to be struck by the falling tree but the more likely it is to strike a fallen tree. Minimum safe stopping distances (Highway Code 1989) and an average vehicle length are used in the calculation of vehicle occupation (Table 1, column 4). The probability of a vehicle striking a

Table 1. Vehicular occupation. The probability of impact $(P)$ is calculated $D 3600 \div S 1000=T ; T V=H 3600 ; H \div 24=P$.

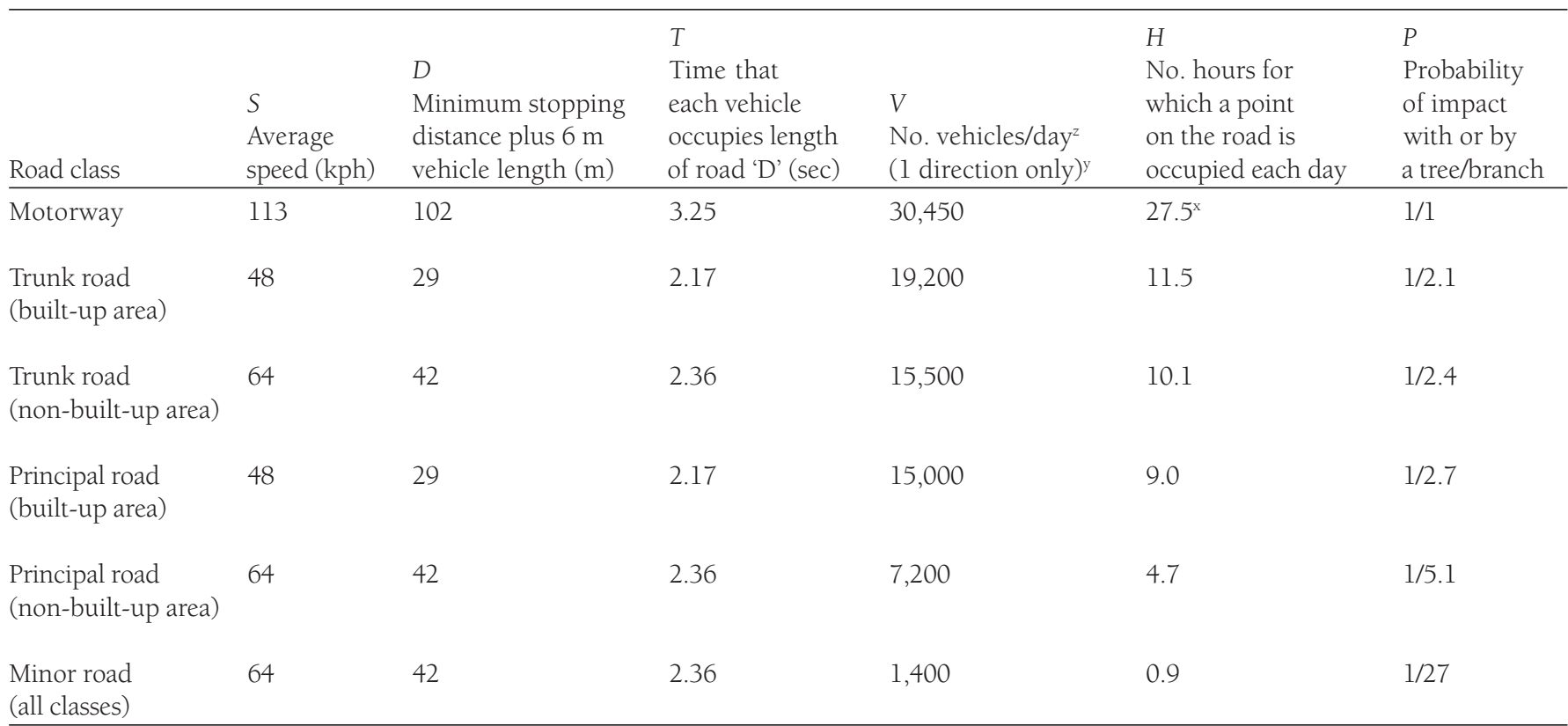

${ }^{2}$ Transport Statistics Great Britain (1997).

${ }^{y}$ For the purpose of assessing the probability of impact, the total number of vehicles occupying all lanes of a motorway traveling in a single direction must be considered.

${ }^{x}$ Due to the sheer volume of traffic using motorways and the need to consider stopping distances, the vehicular occupation period is theoretically greater than $24 \mathrm{~h}$. 
fallen or falling tree is the ratio of the hours a point in the road is occupied by a vehicle-including safe stopping distance-to the hours in a day.

\section{Pedestrians}

The probability of pedestrians occupying a target (Table 2) is calculated on the basis that an individual will spend, on average, 5 seconds occupying the target area, unless a longer occupation is likely, as with a habitable structure or park bench. For example, ten pedestrians per day each occupying the target area for 5 seconds is a daily occupation of 50 seconds, by which the total seconds in a day are divided to give a probability of target occupation. When evaluating pedestrian and vehicular frequency (events) during daylight hours, we must consider whether frequency will be significantly reduced during hours of darkness. The calculation of frequency must in all cases be the total hours in a year divided by the number of events in a year. Although a tree failing during the day might be more likely to strike a mobile target than the same tree at night, it is the frequency of the targets and not the failure of the tree that is most significantly influenced by the time of day. The sum of the higher daytime occupation and the lower nighttime occupation is the daily occupation. Similarly, a single annual event attracting large numbers of visitors could significantly increase the target value and should be included in the assessment.

\section{Structures}

When evaluating a target structure, it is necessary to consider the approximate value of repairs or replacement that might be required if the tree should fail. The values in Table 3 represent cost of repair or replacement.

The ranges of repair value for structures used in Table 3 are derived from a value of "hypothetical life" of $£ 1,000,000$ (US $\$ 1,850,000$ ). For example, target range 2 represents a probability of pedestrian occupation up to $1 / 20 ; £ 1,000,000$ $\div 20=£ 50,000$. Thus, structures likely to incur a repair cost of $£ 50,000$, which is one-twentieth the value of a hypothetical life, are apportioned a ratio of $1 / 20$.

Individual trees should be selected on the basis that they are within striking distance of a significant target or that their failure could result in neighboring trees striking a target. Example 1 (see section titled Calculating Risk of Harm) illustrates that an individual tree cannot represent an unacceptable risk of significant harm if within striking distance of only a target within range 6 (assuming that the tree manager is operating to an acceptable level of risk of $1 / 10,000)$.

Having established that a tree requires assessment, the inspector should assess it according to current practice. Tree inspection procedure is well documented elsewhere (Matheny and Clark 1994; Mattheck and Breloer 1994; Lonsdale 1999) and is not discussed here.

\section{Impact Potential}

A small, dead branch of less than $10 \mathrm{~mm}$ (0.4 in.) diameter is unlikely to cause significant harm even in the case of direct contact with a target, while, on average, a falling branch with a diameter greater than $150 \mathrm{~mm}$ (6 in.) is likely to cause harm in the event of contact with all but the most robust target. The increased potential for injury in relation to the size of tree or branch is proportional to a degree, yet the tree or branch will reach a size where the increased severity of injury is no longer significant. Similarly, most property likely to be affected by tree failure can incur only a limited level of damage before further damage is likely to be inconsequential (i.e., when it is beyond economic repair).

The mass of a falling tree or branch contributes to the force that will occur upon impact with a target but does not alone determine the potential severity of harm. The distance and orientation when falling will influence the force upon impact. Other trees or branches might impede the path of a falling tree or branch, and it might be predicted that the failure of a branch will result in it being hung up without presenting an immediate danger or that it might fall unimpeded. Additionally, a tree or branch may be decayed to such an extent that it will disintegrate or exert only a minor force upon impact. For these reasons, it is probably unrealistic to calculate the effect of the height from which a branch could fall, but it is necessary to be aware that factors other than mass will contribute to the force upon impact, although these factors might be recorded only where they are particularly significant in a given situation.

The system categorizes impact potential by the diameter of tree stems and branches. An allometric biomass equation derived from dry weight measurements of trees of different stem diameters (Tritton and Hornbeck 1982) 
Table 3. Target ranges for structures, pedestrians, and vehicles. Vehicular, pedestrian, and structural targets are categorized by their frequency or monetary value. For example, the probability of a vehicle or pedestrian occupying a target area in target range 4 is between the lower and upper limits of 1/10,000 and 1/500. Using the value of a "hypothetical life" of $£ 1,000,000$ the structure value within the target range 4 is $£ 101-2,000$.

\begin{tabular}{|c|c|c|c|c|}
\hline $\begin{array}{l}\text { Target } \\
\text { range }\end{array}$ & Structure (repair value)* & Pedestrian frequency & Vehicular frequency & $\begin{array}{l}\text { Probability } \\
\text { ratio }{ }^{z}\end{array}$ \\
\hline 1 & $\begin{array}{l}\text { (a) Very high value } \\
\text { (b) Habitable }\end{array}$ & $>36$ per hour-constant & $\begin{array}{l}\text { (a) Motorway } \\
\text { (b) Trunk road, built-up } \\
\text { and non-built-up areas } \\
\text { (c) Principal road, built-up area }\end{array}$ & $1 / 1$ \\
\hline 2 & High value & 10-36 per hour & Principal roads, non-built up-area & $1 / 20$ \\
\hline 3 & Moderate-high value & 1-9 per hour & $\begin{array}{l}\text { Minor roads, moderate use or } \\
\text { poor visibility }\end{array}$ & $1 / 100$ \\
\hline 4 & Moderate value & $<1$ per hour & $\begin{array}{l}\text { Minor roads, low use and good } \\
\text { visibility }\end{array}$ & $1 / 500$ \\
\hline 5 & Low value & $\leq 1$ per day & $\begin{array}{l}\text { Minor private roads and tracks } \\
\text { (no data available) }\end{array}$ & $1 / 10,000$ \\
\hline 6 & Very low value & $\leq 1$ per week & None & $1 / 120,000$ \\
\hline
\end{tabular}

"Structure values represent the likely cost of repair or replacement. Very high $=£ 50,001-1,000,000$; high $=£ 10,001-50,000$; moderate-high $=£ 2,001-10,000 ;$ moderate $=£ 101-2000 ;$ low $=£ 11-100$ : very low $=\leq £ 10$.

is used to produce a data set (Table 4) of comparative dry weight estimates of trees and branches ranging from 10 to $600 \mathrm{~mm}$ (0.4 to $24 \mathrm{in}$.) diameter. An upper limit of $600 \mathrm{~mm}$ has been selected to represent a $1 / 1$ impact potential on the premise that impact from a tree with a stem diameter of 600 $\mathrm{mm}$ (24 in.) has a 1/1 probability of causing maximum possible damage to most frequently encountered targets. From this point, the impact potential reduces to $1 / 23,500$ for a $10 \mathrm{~mm}$ (0.4 in.) branch or tree. For initial assessments, the probabilities are grouped into ranges 1 through 5 in Table 5. Impact potential range 1 represents a range of diameter greater than $450 \mathrm{~mm}$ (18 in.) and is calculated from the estimated dry weight of the $600 \mathrm{~mm}$ (24 in.) diameter tree. Range 1 has a $1 / 1$ probability of causing significant harm upon impact with a target. Range 5 represents 10 to $25 \mathrm{~mm}$ (0.4 to $1 \mathrm{in}$.) diameter and has a probability $1 / 2,500$ of causing significant harm upon impact with a target. If, in exceptional circumstances, the failure of a branch of less than $10 \mathrm{~mm}$ ( $0.4 \mathrm{in}$.) diameter is considered significant, it has a probability of $1 / 23,500$.

\section{Probability of Failure}

Accurately assessing the probability that a tree or branch will fail is highly dependent on the skill and experience of the assessor. This component of the system provides five ranges, each range representing a range of probability of failure within a year, expressed as both a percentage and a ratio calculated from the upper value of that range. Having assessed the tree, the assessor should visualize 100 similar trees in a similar condition in the same environment and estimate how many would be likely to fail during the coming year. If the answer to
Table 4. Biomass dry weight estimates (Tritton and Hornbeck [1982]).

\begin{tabular}{lll}
\hline & $\begin{array}{l}\text { Fraction of dry } \\
\text { Dry weight }(\mathrm{kg}) \\
\text { weight }(600 \mathrm{~mm})\end{array}$ & $\begin{array}{l}\text { we** } \\
\text { as a ratio }\end{array}$ \\
\hline 10 & 0.11263 & $1 / 23,505.722$ \\
25 & 1.0713 & $1 / 2,471.6699$ \\
50 & 5.8876 & $1 / 449.74$ \\
100 & 32.357 & $1 / 81.834$ \\
150 & 87.67 & $1 / 30.203$ \\
200 & 177.82 & $1 / 14.891$ \\
250 & 307.77 & $1 / 8.604$ \\
300 & 481.81 & $1 / 5.496$ \\
350 & 703.8 & $1 / 3.762$ \\
400 & 977.26 & $1 / 2.71$ \\
450 & 1305.5 & $1 / 2.03$ \\
500 & 1691.4 & $1 / 1.566$ \\
550 & 2138 & $1 / 1.24$ \\
600 & 2647 & $1 / 1$ \\
\hline
\end{tabular}

*Diameter at breast height, $1.37 \mathrm{~m}(4.5 \mathrm{ft})$.

$* * x=\mathrm{dbh}(\mathrm{mm}) ; \quad y=$ dry weight estimate; $a=$ allometric coefficient $0.1126294414 ; b=$ allometric coefficient 2.458309949 .

this question is none, then consider 1,000 or 10,000 trees. A probability of failure range 1 to 5 (Table 6) is then selected. Employing this method of assessing probability, inspectors become increasingly aware both of features and conditions that lead to tree failure and of the probability of tree failure. Observing the patterns and frequency of tree failure within this structured framework and applying scientific knowledge to these observations can significantly increase the consistency with which tree inspectors assess the probability of tree failure. 
Table 5. Impact potential.

\begin{tabular}{lll}
\hline Impact potential range & Size of part (mm diameter) likely to impact target & Impact potential \\
\hline $1^{*}$ & $>450$ & $1 / 1$ \\
2 & $251-450$ & $1 / 2$ \\
3 & $101-250$ & $1 / 8.6$ \\
4 & $26-100$ & $1 / 82$ \\
5 & $>10-25$ & $1 / 2,500$ \\
\hline
\end{tabular}

*Range 1 is based on a diameter of $600 \mathrm{~mm}$ (24 in.).

\section{CALCULATING RISK OF HARM}

When working in the field, manual calculation of probabilities is impractical. To facilitate field assessment, a calculator has been developed (Figure 1) comprising three vanes, which are rotated to select values from predetermined ranges of probability and calculate the product of the three component probabilities. The probability ranges are labeled 1 through 6 (Tables 3, 5, and 6 and Figure 1). Alternatively, the probabilities in a spreadsheet format can be loaded onto handheld data collection devices for use with tree inventory software.

Having assessed the hazard and the target, the three component probabilities are selected from the ranges 1 through 6 on the calculator, and the three vanes are aligned to display the result in a window. The calculator displays the result as an index (one thousandth of the reciprocal) of overall probability, which is termed the risk index. For example, if the risk of harm is $1 / 10,000$, the risk index is 10 $(10,000 \div 1000=10)$.

Table 6. Probability of failure. The probability that the tree or selected tree part will fail within a year.

\begin{tabular}{lll}
\hline $\begin{array}{l}\text { Probability of } \\
\text { failure range }\end{array}$ & $\begin{array}{l}\text { Probability of } \\
\text { failure percentage }\end{array}$ & Probability ratio \\
\hline 1 Very high & $51-100$ & $1 / 1$ \\
2 High & $11-50$ & $1 / 2$ \\
3 Moderate & $1-10$ & $1 / 10$ \\
4 Low & $0.1-0.9$ & $1 / 100$ \\
5 Very low & $<0.1$ & $1 / 1,000$ \\
\hline
\end{tabular}

\section{Example 1}

The tree is a $25 \mathrm{~m}(82.5 \mathrm{ft})$ high, mature pedunculate oak (Quercus robur), stem diameter 900 mm (36 in.), in a low use area of woodland with no frequently used paths within $30 \mathrm{~m}$ (100 ft) but with members of the public occasionally entering the target area. There is extensive heartwood decay within the main stem and primary branches. A large opening extends to $30 \%$ of the stem girth from ground level to a height of $1.5 \mathrm{~m}(5 \mathrm{ft})$. The sound stem wall thickness averages $100 \mathrm{~mm}$ (4 in.) and exhibits signs of longitudinal cracking. The crown of the tree contains extensive largediameter dead wood. The most significant part likely to strike the target area is the stem or part of the crown with the weight of the whole tree behind it.

\begin{tabular}{lllll}
\hline & $\begin{array}{l}\text { Target } \\
\text { value }\end{array}$ & $\begin{array}{l}\text { Impact } \\
\text { potential }\end{array}$ & $\begin{array}{l}\text { Probability } \\
\text { of failure }\end{array}$ & $\begin{array}{l}\text { Risk } \\
\text { of harm }\end{array}$ \\
\hline Probability & $1 / 120,000$ & $\times 1 / 1$ & $\times 1 / 1$ & $=1 / 120,000$
\end{tabular}

ratio

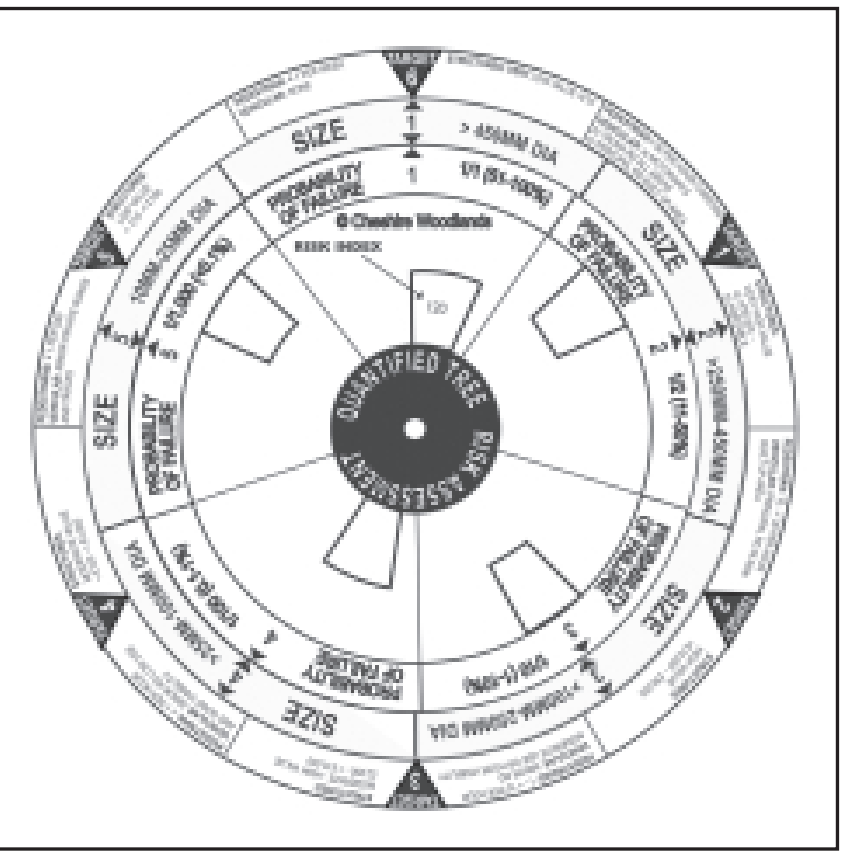

Figure 1. Quantified tree risk assessment calculator illustrating Example 1.

The absence of structures and the very low level of public access indicate that detailed assessment of the tree is not essential. If it could be established that pedestrians are 10 times less likely to visit the woodland in very windy weather, when failure is most likely, the overall probability of harm could be reduced to $1 / 1,200,000$ or less.

If the initial assessment places the risk above or close to the acceptable limit, the risk assessment can be refined using probability $1 / 1$ for any of the components and multiplying the result by the more accurate probability. For 
example, if the highway in example 2 (below) had been accurately surveyed using an electronic traffic counter, and it had been established that the usage was on average seven vehicles per day, it could be stated with confidence that the probability of target occupation was $1 / 5,000$. The risk would then be calculated: impact potential $4 \times$ probability of failure $1 \times$ target value $1=$ risk of harm $1 / 82 . \therefore$ risk of harm $\times$ measured target value $1 / 5,000=$ revised risk of harm $1 / 410,000$.

\section{Example 2}

\section{(Before Remedial Action)}

The tree is a mature beech (Fagus sylvatica) overhanging a minor road with good visibility. The crown of the tree contains long, unstable, dead branches up to $100 \mathrm{~mm}$ (4 in.) diameter. The most significant part likely to strike the target area is deadwood up to $100 \mathrm{~mm}$ diameter.

\begin{tabular}{lllll}
\hline & $\begin{array}{l}\text { Target } \\
\text { value }\end{array}$ & $\begin{array}{l}\text { Impact } \\
\text { potential }\end{array}$ & $\begin{array}{l}\text { Probability } \\
\text { of failure }\end{array}$ & $\begin{array}{l}\text { Risk of } \\
\text { of harm }\end{array}$ \\
\hline Probability ratio & $1 / 100$ & $\times 1 / 82$ & $\times 1 / 1$ & $=1 / 8,200$
\end{tabular}

To reduce the risk to a broadly acceptable level, an overall probability of 1/10,000 must be achieved. Removal of all deadwood is unnecessary. Removal of dead branches greater than $50 \mathrm{~mm}$ (2 in.) diameter overhanging the target should reduce the risk to an acceptable level.

\section{(After Remedial Action)}

\begin{tabular}{lllll}
\hline & $\begin{array}{l}\text { Target } \\
\text { value }\end{array}$ & $\begin{array}{l}\text { Impact } \\
\text { potential }\end{array}$ & $\begin{array}{l}\text { Probability } \\
\text { of failure }\end{array}$ & $\begin{array}{l}\text { Risk } \\
\text { of harm }\end{array}$ \\
\hline Probability ratio & $1 / 100$ & $\times 1 / 450$ & $\times 1 / 1$ & $=1 / 45,000$
\end{tabular}

The predefined ranges used on the calculator are designed to simplify field operation of the system. If a high-value tree is identified as requiring remedial action that will significantly reduce its value, a more detailed evaluation of the target value and probability of failure, establishing probabilities rather than a probability ranges, will provide a more accurate quantification of risk.

\section{DISCUSSION}

Property owners and managers have a duty (under English law) to ensure, insofar as reasonably practicable, that people and property are not exposed to unreasonable levels of risk from the mechanical failure of trees in their control. To achieve this, prudent owners and managers employ arborists to advise on the health, mechanical integrity, and management of trees.

While our knowledge of tree structure, tree defects, and host-pathogen interactions is ever increasing, the dynamic interactions among a diverse range of tree taxa, wooddigesting organisms, and environment are of such complexity that precise quantification of potential for tree failure is unlikely to be achievable. However, with training and the application of a systematic approach, reasonable estimates of probability of tree failure can be achieved.

Evaluation of the targets on which trees might fail might require input from property managers, arborists, and others. Reasonable estimates of target value can be achieved by assessing monetary value and the frequency of target occupation.

Stem or branch weight is probably the most realistic measure of impact potential to apply in the quantification of tree failure risk, and the relationship between diameter and the mass of the stem or branch provides a readily measurable estimate of this component of the risk.

Weather conditions greatly influence tree failure. A walk through woodland and other recreational areas after a moderate storm will often reveal paths and tracks littered with dead and recently living branches. The same weather conditions might result in reduced pedestrian access to recreational areas, substantially reducing the risk of harm from tree failure. Conversely, the risk of branch failure in trees susceptible to summer branch drop (Lonsdale 1999) increases during periods of hot, dry weather when pedestrians might seek shade beneath trees. The influence of weather on tree failure and patterns of pedestrian, equestrian, and cyclist access requires further consideration and research.

The concept of reasonable practicability is a central tenet of English law, which is evident throughout the English Health and Safety legislation and guidance (e.g., Health and Safety at Work Act 1974) and in judgments of the higher courts in relation to tree failure. In regard to trees, this concept should be embraced through the implementation of reasonably practicable tree safety management. If absolute safety from tree failure were achievable, society would almost certainly find the cost in terms of tree losses unacceptable. In this regard, Paine (1971) suggests that "it is high time we admit that we cannot achieve complete safety-and still provide a desirable product - any more than industry can."

The use of quantification in the assessment of tree hazards enables property owners and managers to operate, as far as is reasonably practicable, to a predetermined level of acceptable risk. Application in both urban and rural situations over a period of 8 years indicates that when using the proposed system, risk reduction measures required in high-value target areas are broadly comparable with or below the level of remedial action that might be considered appropriate without the system. In low-value target areas, the risks associated with tree failure hazards are frequently considerably lower than assumed or perceived prior to applying the system. 
Using the proposed system, the assessment of the same tree by different inspectors not trained to a unifying standard has produced variable results, comparison of which indicates that a common standard of training in tree inspection is required. Matheny and Clark (1994) asserted that "training of personnel in field assessment is absolutely essential" and "perhaps the most important aspect of training is to develop consistent evaluation procedures, among individuals and over time." Experience of the proposed system reinforces the view that training of personnel involved in inspection and assessment of trees is in need of standardization. Also lacking standardization is the vocabulary used by tree inspectors. In the United Kingdom, the terms stem, trunk, bole and butt are all used to describe the same part of the tree; this example is by no means isolated. Inconsistent use of terminology can lead to misinterpretation of data by subsequent inspectors, property owners and managers, and by contractors employed to implement remedial measures.

\section{CONCLUSIONS}

Tree safety management should not seek to minimize the risk of harm resulting from tree failure but should balance the benefits of risk reduction with the associated costs in terms of both lost tree value and financial expenditure.

By allocating quantifiable values to the probability of failure and impact potential of trees, and to targets on which trees might fail, the arborist can, with training, assess tree failure hazards with sufficient accuracy that property owners and managers are able to consider the risk of significant harm from tree failure against a level of reasonable or acceptable risk. Using the proposed system, it is possible, not only to identify unacceptable risks, but also to identify the elements of the risk, which, when adjusted, will effectively reduce the overall risk of harm in the most cost efficient or appropriate manner.

The proposed system not only significantly reduces the influence of assessor subjectivity on the outcome of the risk assessment, but it also applies structure to the assessment procedure, requiring detailed assessment of the tree only where there is a significant likelihood of unacceptable risk. By first evaluating and mapping both the general nature of the tree population within an administrative area and the range of targets upon which they could fail, the manager of a large tree population can identify the interface between trees and targets, thus enabling prioritization of risk assessments. A post-mature tree population adjacent to a busy urban thoroughfare might require biannual assessment, whereas the same tree population in a remote wilderness might never be assessed in detail. Between these extremes is a range of inspection frequency, which should be applied as appropriate to the situation.

Use of the system without training leads to misapplication of the data. To ensure, insofar as practicable, that value of the system is maintained through consistent application, the author intends to provide training and ongoing development through a licensing program in the United Kingdom and elsewhere.

\section{LITERATURE CITED}

Henderson, M. 1987. Living with Risk. The British Medical Association Guide. John Wiley and Sons, Chichester, UK. Health and Safety at Work Act. 1974. HMSO, London, UK. Health and Safety Executive. 1995. Generic Terms and Concepts in the Assessment and Regulation of Industrial Risks. Discussion Document. HSE Books, Sudbury, Suffolk, UK. 43 pp.

- 1996. Use of Risk Assessment Within Government Departments. Report prepared by the Interdepartmental Liaison Group on Risk Assessment. HSE Books, Sudbury, Suffolk, UK. 48 pp.

Helliwell, D.R. 1990. Acceptable level of risk associated with trees. Arboric. J. 14(2):159-162.

- 1991. Letters to the editor, Arboric. J. 15(2):179.

Highway Code. 1989. Revised edition. Fifth impression. HMSO, London, UK.

Kirby, K.J., and C.M. Drake. 1993. Dead Wood Matters: The Ecology and Conservation of Saproxylic Invertebrates in Britain. Proceedings of a British Ecological Society Meeting held at Dunham Massey Park on 24 April 1992. English Nature, Peterborough, UK. 105 pp.

Lonsdale, D. 1999. Principles of Tree Hazard Assessment. HMSO, London, UK. 388 pp.

Mattheck, C., and H. Breloer. 1994. The Body Language of Trees. HMSO, London, UK. 241 pp.

Matheny, N.P., and J.R. Clark. 1994. A Photographic Guide to the Evaluation of Hazard Trees in Urban Areas (2nd ed.). International Society of Arboriculture, Champaign, IL. 85 pp.

Paine, L.A. 1971. Accident Hazard Evaluation and Control Decisions on Forested Recreation Sites. USDA Forest Service Research Paper PSW 68. Pacific Southwest Forest and Range Experiment Station, Berkeley, CA. 10 pp.

Transport Statistics Great Britain. 1997. HMSO, London, UK. Tritton, L.M., and J.W. Hornbeck. 1982. Biomass Equations for Major Tree Species. USDA Forest Service General Technical Report NE69. Northeastern Forest Experiment Station, Broomall, PA. 46 pp. 
Acknowledgments. I thank R. Ball, D.R. Helliwell, Dr. D. Lonsdale, S. Miall, L.D. Round, and G. Thomas for their critical comments when reviewing the drafts necessary to bring the project to this stage. I thank S. Coombes, C. Davis, N. Fay, R. Finch, H. Girling, and J. Ryan for their critical comments and valued contributions to a workshop held in 1988 at Alice Holt Lodge, Surrey, to evaluate and trial the system.

\section{Cheshire Woodlands \\ 16 Pickwick Road \\ Poynton, Cheshire \\ England, SK12}

Résumé. Un système d'évaluation des risques associés aux arbres est proposé, ce qui améliore les concepts développés par d'autres et permet de déterminer une probabilité de dommage significatif qui peut être appliquée à l'évaluation du risque de bris d'un arbre. En évaluant les composantes d'un arbre dangereux et en leur attribuant une estimation de leur probabilité de bris, le système proposé permet à un inspecteur arboricole expérimenté de calculer le produit de ces probabilités afin de d'établir une estimation numérique (quantifiée) du risque. L'emploi d'une quantification dans l'évaluation des arbres dangereux permet au propriétaires d'arbres et aux gestionnaires de fonctionner selon des limites prédéterminés de risques raisonnable ou acceptable, et ce aussi loin où cela demeure encore raisonnablement faisable.
Zusammenfassung. Hier wird ein System von Baumrisikobewertung vorgeschlagen, welches weit über die Konzepte von anderen hinausgeht und eine Wahrscheinlichkeit von signifikantem Schaden in Anwendung auf das Baumversagensrisiko ermöglicht. Bei der Bewertung der Komponenten eines Baumversagens und das Vergleichen mit Schätzungen der Wahrscheinlichkeit könnte das vorgeschlagene System den geschulten Bauminspektor zur Kalkulation des Produktes dieser Wahrscheinlichkeiten befähigen, um eine numerische Schätzung der Risiken zu produzieren. Die Nutzung der Quantifikation bei der Bewertung von Baumschäden befähigt den Baumbesitzer und Manager zu handeln, soweit es zu einem vorherbestimmten Limit eines akzeptablen Risiko praktikabel ist.

Resumen. Un sistema de evaluación de riesgo de árboles está propuesto para que expanda los conceptos desarrollados por otros y habilite una probabilidad de daño significativo a ser aplicado en árboles de riesgo. Mediante la evaluación de los componentes de falla de un árbol de riesgo y asignándoles estimadores de probabilidad, el sistema propuesto capacita a inspectores experimentados de árboles para calcular el producto de estas probabilidades para producir una estimación numérica de riesgo. El uso de la cuantificación en la evaluación de árboles de riesgo capacita a los propietarios y manejadores para operar, tanto como sea práctico y razonable, con un predeterminado límite de riesgo aceptable. 